\title{
PENGUKURAN KINERJA INSTALASI FARMASI RSUD DATOE BINANGKANG DENGAN METODE BALANCED SCORECARD BERDASARKAN PERSPEKTIF PELANGGAN SERTA PERSPEKTIF PERTUMBUHAN DAN PEMBELAJARAN
}

\section{PERFORMANCE MEASUREMENT OF PHARMACY INSTALLATION AT RSUD DATOE BINANGKANG BY BALANCED SCORECARD METHOD BASED ON CUSTOMER PERSPECTIVE WITH LEARNING AND GROWTH PERSPECTIVE}

\author{
Wulan P. Tawalujan ${ }^{1)}$, Gayatri Citraningtyas ${ }^{1)}$, Erladys M. Rumondor ${ }^{1)}$ \\ ${ }^{1)}$ Program Studi Farmasi FMIPA UNSRAT Manado, 95115 \\ *wulantawalujan@gmail.com
}

\begin{abstract}
Performance measurement by balanced scorecard method needed to be done at the pharmacy installation of RSUD Datoe Binangkang to see the performance achievements that have been done and the basis for further performance improvement. This research aims to know performance of pharmacy installation of RSUD Datoe Binangkang with the balanced scorecard method based on customer perspective with learning and growth perspective. This research was a non experimental with evaluative descriptive design. The data was collected with retrospective and prospective methods. This research used both qualitative and quantitative data. Qualitative data was obtained by interview and direct observation. Quantitative data was obtained by questionnaires. The result research of performance at customer perspective with patient satisfaction indicator showed that patients have not been satisfied with the services provided with the value of gap for each dimension are: tangibles -0,22, reliability -0,17, responsiveness -0,19, assurance -0,02, emphaty -0,05. Performance at learning and growth perspective with indicators of employee job satisfaction high 3,23, work spirit very high 3,37 and percentage of employee training low 0\%. The conclusion obtained from both perspective were indicators with good performance was job satisfaction and work spirit. Indicators with not good performance that require attention to be improved was employee training and patient satisfaction.
\end{abstract}

Keywords: Performance, Pharmacy Installation, Balanced Scorecard, Customer Perspective, Learning and Growth Perspective.

\begin{abstract}
ABSTRAK
Pengukuran kinerja dengan metode balanced scorecard perlu dilakukan di Instalasi Farmasi RSUD Datoe Binangkang untuk melihat pencapaian kinerja yang telah dilakukan serta dasar bagi perbaikan kinerja selanjutnya. Penelitian ini bertujuan untuk mengetahui kinerja Instalaasi Farmasi RSUD Datoe Binangkang dengan metode balanced scorecard berdasarkan perspektif pelanggan serta perspektif pertumbuhan dan pembelajaran. Penelitian ini merupakan jenis penelitian non eksperimental dengan rancangan deskriptif evaluatif. Data diperoleh secara retrospektif dan prospektif. Kriteria data berupa data kualitatif dan kuantitatif. Data kualitatif melalui wawancara dan observasi langsung. Data kuantitatif melalui kuesioner. Hasil penelitian kinerja pada perspektif pelanggan dengan indikator kepuasan pasien menunjukkan pasien belum puas terhadap pelayanan yang diberikan, dengan perolehan nilai gap pada setiap dimensi yaitu: berwujud $-0,22$, kehandalan $-0,17$, ketanggapan $-0,19$, jaminan $-0,02$, empati $-0,05$. Kinerja pada perspektif pertumbuhan dan pembelajaran dengan indikator kepuasan kerja karyawan tinggi 3,23, semangat kerja karyawan sangat tinggi 3,37, dan persentase pelatihan karyawan rendah $0 \%$. Kesimpulan yang didapat pada kedua perspektif bahwa indikator dengan kinerja yang baik yaitu kepuasan kerja dan semangat kerja. Indikator dengan kinerja yang kurang baik yang memerlukan perhatian untuk diperbaiki yaitu pelatihan karyawan dan kepuasan pasien.
\end{abstract}

Kata Kunci: Kinerja, Instalasi Farmasi, Balanced Scorecard, Perspektif Pelanggan, Perspektif Pertumbuhan dan Pembelajaran. 


\section{PENDAHULUAN}

Saat ini rumah sakit dihadapkan pada penentuan strategi dalam pengelolaan usahanya untuk mencapai pelayanan yang prima. Penentuan strategi akan dijadikan sebagai landasan dan kerangka kerja untuk mewujudkan sasaransasaran kerja yang telah ditentukan oleh manajemen. Penilaian kinerja memegang peranan penting dalam dunia usaha seperti rumah sakit, dikarenakan dengan dilakukanya penilaian kinerja dapat diketahui efektivitas dari penetapan suatu strategi dan penerapanya dalam kurun waktu tertentu (Taher, 2018). Cara untuk mendapatkan penilaian kinerja rumah sakit secara sempurna maka dibutuhkan suatu sistem penilaian kinerja yang mampu mengukur kinerja, salah satu cara yang dapat dilakukan yaitu dengan metode balanced scorecard (Nur, 2016). Metode balanced scorecard dapat diterapkan dalam pelayanan farmasi untuk mencapai pelayanan yang cost effective dan pharmaceutical care yang lebih bermutu. Balanced scorecard merupakan konsep pengukuran kinerja yang komprehensif dan koheren untuk diaplikasikan dalam pengelolaan obat di rumah sakit dalam mengelola strategi dan memperbaiki kinerja dari setiap aspek total (Saharuddin dkk, 2019).

Penggunaan konsep balanced scorecard diharapkan dapat mengurangi kelemahan yang ada pada pengukuran kinerja yang hanya berorientasi pada aspek keuangan saja. Perbedaan yang terdapat dalam konsep ini adalah digunakannya informasi non keuangan sebagai alat ukur kinerja selain informasi keuangan sehingga tidak menekankan pada pencapaian tujuan jangka pendek saja melainkan dapat mengukur penyebab terjadinya perubahan sehingga dapat diantisipasi (Mulia, 2019). Balanced scorecard juga dipercaya sebagai penilaian kinerja yang objektif dan lengkap dari berbagai sudut pandang, baik itu dari sisi eksternal maupun internal. Sisi eksternal yaitu pelanggan Sisi internal yaitu karyawan (Suryani, 2018).

$$
\text { Instalasi Farmasi RSUD Datoe }
$$

Binangkang selalu berupaya memberikan pelayanan kesehatan sesuai dengan kebutuhan pasien dalam meningkatkan kualitas hidup pasien. Peningkatan pelayanan yang bermutu dan berkualitas dapat tercapai dengan adanya peningkatan kinerja karyawan. Metode pengukuran balanced scorecard belum pernah diterapkan di Instalasi Farmasi RSUD Datoe Binangkang sehingga belum diketahui sejauh mana keberhasilan rumah sakit dalam mencapai visi dan tujuan Instalasi Farmasi RSUD Datoe Binangkang di bidang non keuangan, tujuan jangka panjang serta sisi eksternal dan internal. Berdasarkan uraian latar belakang tersebut, penulis merasa tertarik melakukan penelitian tentang pengukuran kinerja Instalasi Farmasi RSUD Datoe Binangkang dengan metode balanced scorecard berdasarkan perspektif pelanggan serta perspektif pertumbuhan dan pembelajaran.

\section{METODOLOGI PENELITIAN}

\section{Waktu dan Tempat Penelitian}

Penelitian ini dilaksanakan di Instalasi Farmasi RSUD Datoe Binangkang pada bulan Oktober 2019 - Maret 2020.

\section{Jenis dan Rancangan Penelitian}

Penelitian ini merupakan jenis penelitian non eksperimental dengan rancangan deskriptif evaluatif. Data diperoleh secara retrospektif dan prospektif. Kriteria data berupa data kualitatif dan kuantitatif. Data kualitatif diperoleh melalui wawancara dan observasi langsung. Data kuantitatif diperoleh melalui kuesioner.

\section{Alat dan Bahan \\ Alat}

Alat yang digunakan dalam penelitian ini adalah alat tulis menulis, lembar kuesioner dan kamera untuk dokumentasi.

\section{Bahan}

Bahan yang digunakan dalam penelitian ini bersumber dari dua data yaitu data primer dan data sekunder:

1. Data Primer

Data primer yang digunakan yaitu kuesioner untuk pasien rawat jalan yang menebus obat di Instalasi Farmasi RSUD Datoe Binangkang, kuesioner untuk karyawan Instalasi Farmasi RSUD Datoe Binangkang, wawancara serta observasi langsung.

2. Data Sekunder

Data sekunder yang digunakan yaitu data jumlah pasien rawat jalan yang menebus obat di Instalasi Farmasi RSUD Datoe Binangkang 
selama 1 bulan dan data jumlah karyawan Instalasi Farmasi RSUD Datoe Binangkang.

\section{Populasi dan Sampel}

Populasi dalam penelitian ini berdasarkan perspektif pelanggan yaitu pasien rawat jalan yang menebus obat di Instalasi Farmasi RSUD Datoe Binangkang, berdasarkan perspektif pertumbuhan dan pembelajaran yaitu seluruh karyawan Instalasi Farmasi RSUD Datoe Binangkang.

Sampel yang digunakan dalam penelitian ini adalah pasien rawat jalan yang menebus obat di Instalasi Farmasi RSUD Datoe Binangkang dan 12 karyawan Instalasi Farmasi RSUD Datoe Binangkang. Berdasarkan perspektif pelanggan, digunakan Rumus Slovin untuk menentukan besaran sampel (Sugiyono, 2013).

$$
\begin{aligned}
& n=\frac{N}{1+N e^{2}} \\
& n=\frac{840}{1+\left(840 \times 0,05^{2}\right)} \\
& n=\frac{840}{3,1} \\
& n=270,96=271
\end{aligned}
$$

$$
\begin{aligned}
& \text { Keterangan } \\
& \mathrm{n}=\text { ukuran sampel } \\
& \mathrm{N}=\text { ukuran populasi } \\
& \mathrm{e}=\text { penelitian ini menggunakan derajat } \\
& \quad \begin{array}{l}
\text { kepercayaan } 95 \% \text { maka tingkat kesalahan } \\
\text { dalam penelitian ini adalahf } 5 \% \text { atau } 0,05
\end{array}
\end{aligned}
$$

\section{Uji Validitas dan Reliabilitas}

Uji validitas merupakan suatu alat pengukuran untuk mengukur apa yang diukur guna menunjukkan tingkat kesahihan suatu instrumen (Dahlan, 2010). Alat ukur yang digunakan dalam penelitian ini adalah kuesioner. Sebelum kuesioner digunakan dalam penelitian, kuesioner dilakukan uji validitas terlebih dahulu. Kuesioner dinyatakan valid jika $r$ hitung $\geq r$ tabel (Dahlan, 2012).

Setiap item yang dinyatakan valid, selanjutnya dilakukan uji reliablitas. Uji reliabilitas dilakukan dengan cara membandingkan angka Cronbach's alpha dengan ketentuan nilai Cronbach's alpha. Uji ini dilakukan untuk menunjukkan sejauh mana suatu alat pengukur dapat dipercaya jika dilakukan pengukuran berulang dengan alat yang sama
(Notoatmodjo, 2012). Pengujian reliabilitas biasanya menggunakan batasan tertentu seperti 0,6 (Priyatno, 2010).

\section{Analisis Data}

Data dikumpulkan menggunakan observasi langsung, wawancara serta kuesioner. Data yang diperoleh dikelompokkan menjadi data kualitatif dan data kuantitatif. Data kualitatif melalui wawancara dan observasi langsung. Data kuantitatif melalui kuesioner kepuasan pasien, kuesioner kepuasan kerja karyawan dan kuesioner semangat kerja karyawan. Masing-masing kuesioner diolah menjadi skor dengan menggunakan skala Likert. Skala Likert penilaian kuesioner yang digunakan mengacu pada Azwar (1999) yang dapat dilihat pada Tabel 1.

Tabel 1. Penilaian Kuesioner

\begin{tabular}{cc}
\hline Range Skor & Kriteria Penilaian \\
\hline $1,0 \leq \mathrm{x} \leq 1,75$ & Sangat Rendah \\
\hline $1,75 \leq \mathrm{x} \leq 2,5$ & Rendah \\
\hline $2,5 \leq \mathrm{x} \leq 3,25$ & Tinggi \\
\hline $3,25 \leq \mathrm{x} \leq 4,0$ & Sangat Tinggi \\
\hline
\end{tabular}

Kuesioner yang telah terisi dengan jawaban responden dan dinyatakan telah memenuhi kriteria penelitian selanjutnya dilakukan uji validitas dan reliabilitas menggunakan aplikasi SPSS. Setelah dilakukan penilaian dengan menggunakan skala Likert pada semua responden, selanjutnya dilakukan analisis distribusi skor pada jawaban responden dari masing-masing kuesioner yang dijumlahkan lalu dihitung nilai rata-ratanya. Perhitungan penilaian mengacu pada range skor kuesioner Harsono (2010) yang dapat dilihat pada Tabel 2.

Tabel 2. Range Skor Kuesioner

\begin{tabular}{ccc}
\hline $\begin{array}{c}\text { Jawaban } \\
\text { favourable }\end{array}$ & Nilai & $\begin{array}{c}\text { Jawaban } \\
\text { unfavourable }\end{array}$ \\
\hline Sangat Setuju & 4 & $\begin{array}{c}\text { Sangat Tidak } \\
\text { Setuju }\end{array}$ \\
\hline Setuju & 3 & Tidak Setuju \\
\hline Tidak Setuju & 2 & Setuju \\
\hline $\begin{array}{c}\text { Sangat Tidak } \\
\text { Setuju }\end{array}$ & 1 & Sangat Setuju \\
\hline
\end{tabular}

Analisis gap lima dimensi kualitas pelayanan hanya dilakukan pada indikator kepuasan pasien. Pengukuran kualitas dalam model servqual (tangible, reliability, 
responsiveness, assurance emphaty) didasarkan pada skala multi-item yang dirancang untuk mengukur ekspektasi dan persepsi pelanggan, serta gap diantara keduanya pada lima dimensi utama kualitas pelayanan. Kesenjangan ( gap) lima dimensi kualitas pelayanan menggambarkan selisih antara persepsi pasien atas pelayanan yang diterima di Instalasi Farmasi RSUD Datoe Binangkang dengan pelayanan yang diharapkan pasien di Instalasi Farmasi RSUD Datoe Binangkang. Menurut Faramita (2013) rumus untuk menghitung skor penilaian servqual untuk setiap pasang persahnyataan bagi masing-masing pelanggan menggunakan rumus sebagai berikut :

Skor servqual $=$ skor realita - skor ekspektasi

\section{HASIL DAN PEMBAHASAN}

\section{Perspektif Pelanggan}

\section{a. Karakteristik Responden}

Karakteristik dari responden dalam penelitian ini meliputi jenis kelamin, usia, pendidikan terakhir dan jenis pekerjaan.

Tabel 3. Karakteristik Responden

\begin{tabular}{clcc}
\hline No. & Karakteristik Responden & n & (\%) \\
\hline 1. & Jenis Kelamin & & \\
& Laki-laki & 79 & 29,2 \\
& Perempuan & 192 & 70,8 \\
\hline 2. & Usia (Depkes, 2009) & & \\
& 17 - 25 Tahun & 15 & 5,5 \\
& (Masa Remaja Akhir) & & \\
& 26 - 35 Tahun & 57 & 21,1 \\
& (Masa Dewasa Awal) & & \\
& 36 - 45 Tahun & 77 & 28,4 \\
& (Masa Dewasa Akhir) & & \\
& 46 - 55 Tahun & 76 & 28 \\
& (Masa Lansia Awal) & & \\
& 56 - 65 Tahun & 36 & 13,3 \\
& (Masa Lansia Akhir) & & \\
& > 65 Tahun & 10 & 3,7 \\
& (Masa Manula) & & \\
\hline 3. & Pendidikan Terakhir & & \\
& SD & 54 & 19,9 \\
& SLTP & 70 & 25,8 \\
& SLTA & 107 & 39,5 \\
& Perguruan Tinggi & 40 & 14,8 \\
\hline 4. & Pekerjaan & & \\
& PNS & 27 & 10 \\
& Wiraswasta & 44 & 16,2 \\
& Petani & 50 & 18,4 \\
\hline & & &
\end{tabular}

\begin{tabular}{lcc}
\hline Ibu Rumah Tangga & 130 & 48 \\
Lainnya & 20 & 7,4 \\
\hline
\end{tabular}

Berdasarkan data pada tabel 3 menunjukkan responden terbanyak berjenis kelamin perempuan yakni sebanyak 192 pasien (70,8\%). Pada karakteristik usia, mayoritas berada pada kelompok usia 36-45 tahun (masa dewasa akhir) yaitu berjumlah 77 orang $(28,4 \%)$. Pada karakteristik pendidikan, responden terbanyak dengan pendidikan terakhir SLTA sebanyak 107 orang $(39,5 \%)$. Karakteristik responden pekerjaan yang terbesar adalah pasien rawat jalan sebagai ibu rumah tangga sebanyak 130 orang (48\%).

\section{b. Uji Validitas dan Reliabilitas}

Uji validitas untuk kuesioner kinerja dan harapan diberikan pada 30 responden pada awal penelitian. Kuesioner yang diberikan berisi 18 item pernyataan dengan menggunakan metode Servqual (service quality) yang terdiri dari 5 dimensi kualitas pelayanan yaitu tangibles, reliability, responsiveness, assurance dan emphaty. Data yang diperoleh akan dimasukkan dalam lembar kerja SPSS dan diuji validitas. Nilai $\mathrm{r}$ hitung hasil uji validitas menggunakan SPSS selanjutnya dibandingkan dengan nilai $\mathrm{r}$ tabel yaitu 0,361 (Priyatno, 2010). Berdasarkan hasil dari SPSS, dapat disimpulkan bahwa semua item dinyatakan valid karena nilai $\mathrm{r}$ hitung melebihi nilai $r$ tabel $(0,361)$, sehingga seluruh item pernyataan bisa disebarkan untuk responden sesuai dengan jumlah sampel penelitian.

Setiap item pernyataan yang telah dinyatakan valid, selanjutnya dilakukan uji reliabilitas dan dilihat nilai Cronbach's Alpha dari kuesioner harapan dan kinerja. Kuesioner harapan dan kinerja dinyatakan reliabel dilihat dari nilai koefisien Cronbach's Alpha yang > 0,6. Berdasarkan hasil dari SPSS, kuesioner harapan memiliki nilai Cronbach's Alpha sebesar 0,849 dan kuesioner kinerja memiliki nilai Cronbach's Alpha sebesar 0,840. Hasil uji reliabilitas dari kedua aspek tersebut menunjukkan bahwa setiap item pernyataan dinyatakan reliabel karena keduanya memiliki nilai koefisien Cronbach's Alpha $>0,6$.

\section{c. Kepuasan Pelanggan}

Pengukuran kepuasan pasien digunakan untuk mengetahui sejauh mana kinerja yang dilakukan karyawan Instalasi Farmasi RSUD 
Datoe Binangkang sesuai dengan harapan pasien rawat jalan sebagai tolak ukur mengenai kinerja apa saja yang perlu dibenahi serta ditingkatkan. Analisis gap menggambarkan selisih antara pelayanan yang diterima pasien rawat jalan terhadap pelayanan yang diharapkan. Idealnya nilai gap adalah nol, yang berarti kinerja yang diberikan telah sesuai dengan harapan pasien. Angka negatif menunjukkan adanya harapan pasien yang belum terpenuhi. Angka positif menunjukkan bahwa kinerja yang diberikan telah melebihi harapan pasien (Aini, 2017). Adanya perbedaan antara persepsi harapan pasien terhadap pelayanan yang diterima akan mempengaruhi tingkat kepuasan pasien. Data hasil analisis gap lima dimensi kualitas pelayanan dapat dilihat pada Tabel 4.

Tabel 4. Analisis Gap Antara Kinerja dan Harapan Pada Lima Dimens Kualitas Pelayanan

\begin{tabular}{clcccc}
\hline No. & Dimensi & Skor Kinerja & Skor Harapan & Gap & Peringkat \\
\hline 1. & Tangibles & 3,06 & 3,28 & $-0,22$ & 5 \\
\hline 2. & Reliability & 3,09 & 3,26 & $-0,17$ & 3 \\
\hline 3. & Responsiveness & 3,11 & 3,30 & $-0,19$ & 4 \\
\hline 4. & Assurance & 3,28 & 3,30 & $-0,02$ & 1 \\
\hline 5. & Emphaty & 3,26 & 3,31 & $-0,05$ & 2 \\
\hline \multicolumn{7}{l}{ Skor Total } & 3,16 & 3,29 & $-0,13$ & menyebabkan banyak pasien yang berdiri, \\
& Gap yang diperoleh dari masing-masing & $\begin{array}{l}\text { akibatnya pasien merasa kurang nyaman pada saat } \\
\text { mengantri obat. Penelitian yang dilakukan oleh }\end{array}$
\end{tabular}
pelayanan yang diharapkan terhadap pelayanan yang diterima pasien rawat jalan di Instalasi Farmasi RSUD Datoe Binangkang yang pada akhirnya akan menentukan kepuasan pasien atau ketidakpuasan pasien terhadap pelayanan yang diberikan oleh Instalasi Farmasi RSUD Datoe Binangkang. Berdasarkan data pada Tabel 4, total nilai kepuasan pasien $-0,13$. Hal ini berarti pasien rawat jalan merasa belum puas terhadap pelayanan di Instalasi Farmasi RSUD Datoe Binangkang. Dimana harapan pasien lebih besar dari pada kinerja karyawan, keadaan ini yang dapat menyebabkan kualitas pelayanan menjadi tidak sesuai dengan harapan pasien terhadap kinerja yang ada di Instalasi Farmasi RSUD Datoe Binangkang. Adanya perbedaan antara persepsi harapan pasien terhadap pelayanan yang diterima akan mempengaruhi tingkat kepuasan pasien.

Dimensi tangibles memiliki nilai gap terbesar dari lima dimensi kualitas pelayanan sehingga sangat perlu diperhatikan oleh pihak Instalasi Farmasi RSUD Datoe Binangkang agar menjadi prioritas untuk ditangani dengan cepat. Hal ini dikarenakan pasien belum merasa puas terhadap fasilitas tempat duduk di Instalasi Farmasi karena terdapat beberapa tempat duduk yang rusak serta tempat duduk yang tersedia belum memenuhi banyaknya kunjungan pasien khususnya pada saat jam-jam sibuk sehingga
Helmawati (2014) menyatakan bahwa dimensi tangibles yang berfokus pada pengaturan desain dan tata letak lingkungan yang bersih dan nyaman serta mengutamakan penampilan karyawan yang rapi akan mendukung proses layanan menjadi lebih baik dan menciptakan lingkungan yang kondusif bagi pasien. Lingkungan tersebut dapat mempengaruhi respon emosional dan psikis pasien yang kemudian mempengaruhi tingkat kesembuhan pasien. Adanya tingkat kesembuhan pasien yang tinggi dapat meningkatkan kepuasan pasien serta meningkatkan minat kunjungan ulang ke rumah sakit yang bersangkutan.

Dimensi reliability berada pada peringkat ketiga. Hal ini dikarenakan banyak pasien yang belum diberikan penjelasan mengenai efek samping dari obat yang diterima, akibatnya pasien belum merasa puas dan berharap adanya perbaikan yaitu dengan menjelasakan efek samping obat agar pasien tidak khawatir akan penggunaan obat selama terapi. Hasil penelitian ini sejalan dengan penelitian yang dilakukan oleh Isnandar dkk (2013) yang menunjukkan hasil negatif terhadap pelayanan dimensi reliability, maka perlu diadakannya sebuah program dengan tujuan untuk menambah wawasan dan pengetahuan petufgas di Instalasi Farmasi dalam memberikan pelayanan terkait dengan dimensi 
kehandalan, seperti diadakannya pelatihan dan seminar.

Dimensi responsiveness berada pada peringkat keempat. Waktu tunggu pelayanan resep di Instalasi Farmasi yang terlalu lama disebabkan oleh banyaknya resep yang menumpuk terutama pada jam-jam sibuk yaitu antara pukul 11.00 hingga pukul 13.00 dikarenakan pada jam tersebut pasien baru mendapatkan resep dari masingmasing poli rawat jalan, sehingga pasien harus mengantri terlalu lama hingga mencapai 1 sampai 2 jam lebih untuk mendapatkan obat. Hal ini membuat pasien merasa kurang puas terhadap pelayanan Instalasi Farmasi RSUD Datoe Binangkang dan berharap adanya perbaikan. Berdasarkan observasi, Instalasi Farmasi memiliki shift 3 orang perhari selama 24 jam yang terdiri dari 1 Apoteker untuk melayani pasien dengan rata-rata resep rawat jalan yang masuk perhari kira-kira 20an resep. Sesuai dengan Peraturan Menteri Kesehatan Nomor 72 Tahun 2016 tentang Standar Pelayanan Kefarmasian di Rumah Sakit, penghitungan kebutuhan Apoteker berdasarkan beban kerja pada Pelayanan Kefarmasian di rawat jalan idealnya dibutuhkan tenaga Apoteker dengan rasio 1 Apoteker untuk 50 pasien. Dilihat dari resep rawat jalan yang masuk perhari jika dibandingkan dengan rasio Apoteker, maka seharusnya pelayanan bisa dilakukan lebih cepat. Menurut Keputusan Menteri Kesehatan Nomor 129 Tahun 2008 tentang Standar Pelayanan Minimal Rumah Sakit, waktu tunggu obat jadi (non racikan) selama $\leq 30$ menit dan waktu tunggu obat racikan selama $\leq 60$ menit. Dilihat dari waktu tunggu pelayanan kefarmasian yang belum sesuai dengan standar pelayanan, maka perlu dilakukan upaya perbaikan meningkatkan kepuasan pasien yaitu diharapkan pihak Apoteker di Instalasi Farmasi Rumah Sakit lebih sigap dalam pelayanan, maupun penambahan loket obat atau penambahan karyawan yang dapat mempercepat penyerahan obat kepada pasien sehingga waktu tunggu pelayanan resep dapat diminimalkan dan pelayanan dapat dilaksanakan secara optimal. Pelayanan yang demikian sangat memberikan dorongan bagi pasien sehingga mendukung dalam pelaksanaan terapi. Hal ini sejalan dengan pendapat Kaplan dan Norton (2004) dalam Satibi dkk (2011) yang menyatakan bahwa faktor pendorong kepuasan dan kepercayaan pelanggan, yaitu proses pelayanan yang bermutu atau tidak terjadi kesalahan dalam pelayanan dan proses waktu yang cepat. Sebaliknya, seringnya terjadi kesalahan dalam pelayanan dan proses pelayanan yang lama dapat menurunkan kepuasan pelanggan.

Dimensi assurance memiliki nilai gap terkecil dari lima dimensi kualitas pelayanan. Hal ini menunjukkan bahwa kinerja yang dilakukan oleh karyawan Instalasi Farmasi RSUD Datoe Binangkang terhadap dimensi assurance sudah cukup besar hampir sesuai dengan harapan pasien, sehingga gap antara kinerja karyawan dengan harapan pasien rawat jalan pada dimensi ini lebih kecil dibandingkan dengan dimensi lainnya. Hal ini menunjukkan masih ada aspek yang perlu dibenahi, sekalipun pasien sudah merasa cukup puas. Pasien menilai bahwa bahwa karyawan Instalasi Farmasi bersikap kurang ramah dalam melayani pasien. Pasien beranggapan mungkin dikarenakan karyawan sangat sibuk dan harus terburu-buru melayani pasien yang lain, khususnya pada saat jam-jam sibuk, sehingga hal ini mempengaruhi kepuasan pasien terhadap pelayanan yang diberikan oleh Instalasi Farmasi. Menurut Zainaro dkk (2018), pelayanan yang baik harus disertai dengan sikap keramahan kepada pihak yang dilayani. Untuk meningkatkan keramahan di bidang pelayanan kesehatan seperti pelayanan kefarmasian, perlu membangun budaya kerja bermutu yaitu budaya tidak ada kesalahan yang diterapkan mulai dari pimpinan sampai ke karyawan yang langsung berhubungan dengan pasien. Budaya kerja seperti ini perlu diterapkan untuk membentuk kelompok kerja yang kompak dan mendapat pelatihan secara terus menerus sesuai dengan perkembangan teknologi dan ekspektasi pasien.

Dimensi emphaty berada pada urutan peringkat kedua. Hal ini dinilai oleh pasien bahwa karyawan memberikan pelayanan dengan memandang status sosial dimana hanya sebagian orang saja yang mendapat perhatian khusus. Berdasarkan observasi, pada saat mengantri obat pasien umum lebih dulu mendapatkan pelayanan daripada pasien BPJS. Berdasarkan analisis gap yang menunjukkan nilai negatif, masih ada perbedaan/ketidaksesuaian antara harapan pasien dengan kualitas pelayanan terhadap kinerja yang dirasakan pasien. Dimana pasien menuntut karyawan Instalasi Farmasi untuk dapat memberikan pelayanan yang mengutamakan perhatian secara pribadi kepada pasien. Hasil penelitian ini sejalan dengan penelitian yang dilakukan oleh Isnandar dkk (2013) yang menunjukkan hasil negatif terhadap pelayanan dimensi emphaty, menyatakan perlu adanya pelatihan dalam hal keterampilan antar pribadi 
khususnya menyangkut interaksi dengan pasien. Menurut Sumiati (2019) indikator-indikator pada dimensi emphaty merupakan perwujudan dari aspek intangible yang menekankan betapa besarnya peran karyawan dalam menjalin komunikasi efektif terhadap pasien sebagai salah satu cara meningkatkan kualitas pelayanan kefarmasian.

\section{Perspektif Pertumbuhan dan Pembelajaran}

a. Kepuasan Kerja Karyawan

Tabel 5. Rata-rata Kepuasan Kerja Karyawan Instalasi Farmasi RSUD Datoe Binangkang

\begin{tabular}{|c|c|c|c|}
\hline No. & Pernyataan & $\begin{array}{c}\text { Nilai } \\
\text { Rata- } \\
\text { rata }\end{array}$ & Kategori \\
\hline 1. & $\begin{array}{l}\text { Kepuasan } \\
\text { terhadap uang } \\
\text { jasa }\end{array}$ & 2,58 & Tinggi \\
\hline 2. & $\begin{array}{l}\text { Kepuasan pada } \\
\text { pekerjaan }\end{array}$ & 3,16 & Tinggi \\
\hline 3. & $\begin{array}{l}\text { Kepuasan } \\
\text { terhadap } \\
\text { pengawasan } \\
\text { selama bekerja }\end{array}$ & 3,33 & $\begin{array}{l}\text { Sangat } \\
\text { Tinggi }\end{array}$ \\
\hline 4. & $\begin{array}{l}\text { Kepuasan pada } \\
\text { hubungan dengan } \\
\text { Kepala Instalasi }\end{array}$ & 3,50 & $\begin{array}{l}\text { Sangat } \\
\text { Tinggi }\end{array}$ \\
\hline 5. & $\begin{array}{l}\text { Kepuasan } \\
\text { terhadap promosi } \\
\text { jabatan }\end{array}$ & 3,25 & Tinggi \\
\hline 6. & $\begin{array}{l}\text { Kepuasan } \\
\text { terhadap jam } \\
\text { kerja }\end{array}$ & 3,41 & $\begin{array}{l}\text { Sangat } \\
\text { Tinggi }\end{array}$ \\
\hline 7. & $\begin{array}{l}\text { Kepuasan } \\
\text { terhadap } \\
\text { pembagian tugas } \\
\text { kerja }\end{array}$ & 3,16 & Tinggi \\
\hline 8. & $\begin{array}{l}\text { Kepuasan pada } \\
\text { hubungan dengan } \\
\text { teman-teman }\end{array}$ & 3,50 & $\begin{array}{l}\text { Sangat } \\
\text { Tinggi }\end{array}$ \\
\hline & Rata-rata & 3,23 & Tinggi \\
\hline
\end{tabular}

Berdasarkan data pada Tabel 5, menunjukkan rata-rata tingkat kepuasan kerja karyawan berada pada kategori tinggi. Nilai terendah berada pada pernyataan 1 yaitu kepuasan terhadap uang jasa yang diperoleh berada pada nilai terendah. Hal ini disebabkan karena karyawan merasa uang jasa yang diperoleh belum sesuai dengan beban kerja yang ada. Selain itu tidak semua karyawan memperoleh uang jasa yang sama, dimana karyawan yang sudah Pegawai Negeri Sipil mendapat penghasilan yang lebih besar dibandingkan dengan Pegawai Kontrak. Nilai tertinggi berada pada pernyataan 4 dan 8 yaitu kepuasan pada hubungan dengan Kepala Instalasi dan hubungan dengan teman-teman, dikarenakan terjalin hubungan yang baik antar sesama karyawan maupun dengan Kepala Instalasi dengan cara saling menghargai dan menghormati serta komunikasi yang baik demi tercapainya tujuan bersama. Menurut Buitenbach dan De Witt (2005) dalam Saharuddin dkk (2019) karyawan yang senang dan puas terhadap pekerjaannya dapat meningkatkan produktivitas kerja sehingga hasilnya akan meningkatkan komitmen karyawan terhadap organisasi.

\section{b. Semangat Kerja Karyawan}

Tabel 6. Hasil Pengukuran Skala Semangat Kerja Karyawan Instalasi Farmasi RSUD Datoe Binangkang

\begin{tabular}{ccc}
\hline Keterangan & $\begin{array}{c}\text { Skala } \\
\text { Semangat } \\
\text { Kerja }\end{array}$ & Keterangan \\
\hline Rata-rata & 3,37 & Sangat Tinggi \\
Minimal & 2,91 & Tinggi \\
Maksimal & 3,75 & Sangat Tinggi \\
\hline
\end{tabular}

Berdasarkan data pada Tabel 6, menunjukkan nilai rata-rata tingkat semangat kerja karyawan berada pada kategori sangat tinggi, sehingga hal ini akan berpengaruh pada kinerja Instalasi Farmasi RSUD Datoe Binangkang karena semangat kerja yang baik seiring dengan adanya loyalitas petugas terhadap perusahaan (Rao, 2009). Dimana karyawan dengan loyalitas yang tinggi selalu mempunyai semangat dalam melaksanakan setiap tugas dan pekerjaanya dengan baik untuk memajukan Rumah Sakit. Hal ini harus terus ditingkatkan dan diperhatikan faktor-faktor yang mempengaruhi semangat kerja karyawan. Menurut Satibi (2007) dalam Saharuddin dkk (2019) semangat kerja karyawan yang tinggi didukung oleh adanya kesesuaian job desk dari masing-masing karyawan dengan tingkat pendidikan dan keahliannya, selain itu semangat kerja tinggi juga dipengaruhi oleh 
tugas, wewenang, serta jabatannya. Instalasi Farmasi RSUD Datoe Binangkang selama ini belum ada pengadaan sistem reward seperti bonus kepada karyawan yang memiliki kinerja yang tinggi, namun demi meningkatkan semangat kerja karyawan, Kepala Instalasi Farmasi RSUD Datoe Binangkang saling bertukar pikiran dengan karyawan terkait kendala-kendala yang terjadi di Instalasi Farmasi RSUD Datoe Binangkang dan saling memberikan semangat sehingga hal tersebut diharapkan dapat meningkatkan semangat kerja karyawan.

\section{c. Pelatihan Karyawan}

Pelatihan karyawan ini sangat diperlukan untuk menambah pengetahuan dan keterampilan karyawan sehingga dapat meningkatkan kinerja pelayanan Instalasi Farmasi yang berdampak pada kepuasan pasien terhadap pelayanan. Karyawan Instalasi Farmasi rumah sakit sebagai salah satu motor penggerak rumah sakit yang berada digaris depan dalam memberikan pelayanan kepada pasien sudah seharusnya menjadi pelatihan terkait dpeningkatan kapabilitas dan kompetensinya sehingga dapat berkontribusi positif terhadap rumah sakit (Harsono, 2010). Persentase pelatihan karyawan di Instalasi Farmasi RSUD Datoe Binangkang ialah 0\% dimana karyawan Instalasi Farmasi belum pernah mendapatkan pelatihan dalam mendukung pekerjaannya. Kurangnya pelatihan bagi karyawan menyebabkan kinerja karyawan menjadi kurang baik sehingga belum mampu memberikan pelayanan sesuai dengan harapan pasien. Menurut Kepala Instalasi Farmasi hal ini dikarenakan dana untuk melaksanakan pelatihan tidak ada. Dalam Peraturan Menteri Kesehatan Nomor 72 Tahun 2016 tentang Standar Pelayanan Kefarmasian di Rumah Sakit menyatakan bahwa setiap staf harus diberi kesempatan untuk meningkatkan pengetahuan dan keterampilannya.

\section{KESIMPULAN}

Pengukuran kinerja Instalasi Farmasi RSUD Datoe Binangkang dengan menggunakan metode balanced scorecard berdasarkan perspektif pelanggan serta perspektif pertumbuhan dan pembelajaran dapat disimpulkan bahwa indikator dengan hasil kinerja yang baik yaitu kepuasan kerja karyawan dan semangat kerja karyawan. Hal ini dilihat dari hasil yang diperoleh dengan kepuasan kerja karyawan yang tinggi 3,23 dan semangat kerja karyawan yang sangat tinggi 3,37. Hasil kinerja yang kurang baik yang memerlukan perhatian untuk diperbaiki yaitu pelatihan karyawan dan kepuasan pasien. Hal ini dilihat dari hasil yang diperoleh dengan pelatihan karyawan sebesar 0\% dan kepuasan pasien dengan rata-rata nilai gap sebesar $-0,13$ dengan nilai gap pada setiap dimensi pelayanan berwujud $-0,22$, kehandalan $-0,17$, ketanggapan $-0,19$, jaminan 0,02 dan empati $-0,05$.

\section{SARAN}

Perlu adanya peningkatan pelayanan kesehatan di Instalasi Farmasi RSUD Datoe Binangkang dalam mempertimbangkan kebutuhan dan kepuasan pasien dengan cara memperhatikan waktu tunggu pelayanan resep, ketersediaan obat, peningkatan fasilitas di ruang tunggu, serta diharapkan untuk mengadakan pelatihan bagi karyawan dalam meningkatkan kinerja karyawan sesuai harapan pasien.

\section{DAFTAR PUSTAKA}

Aini, N. 2017. Evaluasi Kinerja Instalasi Farmasi RSUD A. W. Sjahranie Samarinda dengan Pendekatan Balanced Scorecard [Tesis]. Universitas Setia Budi, Surakarta.

Azwar, S. 1999. Penyusunan Skala Psikologi. Pustaka Pelajar, Yogyakarta.

Dahlan, S. M. 2010. Besar Sampel dan Cara Pengambilan Sampel dalam Penelitian Kedokteran dan Kesehatan. Salemba Medika, Jakarta.

Dahlan, S. M. 2012. Statistik Untuk Kedokteran dan Kesehatan. Salemba Medika, Jakarta.

Departemen Kesehatan RI. 2009. Kategori Umur. Kementerian Kesehatan RI, Jakarta.

Faramita, R. 2013. Analisis Kinerja Instalasi Farmasi RSUD KRT. Setjonegoro Kabupaten Wonosobo Jawa Tengah dengan Pendekatan Balanced Scorecard [Tesis]. Universitas Setia Budi, Surakarta.

Harsono. 2010. Analisis Kinerja Instalasi Farmasi Rumah Sakit Medika Mulya Wonogiri dengan Pendekatan Balanced Scorecard [Tesis]. Universitas Setia Budi, Surakarta. 
Helmawati, T., Handayani, S. 2014. Pengaruh Kualitas Layanan Terhadap Minat Kunjungan Ulang yang Dimediasi oleh Kepuasan Pasien di Klinik Rumah Zakat Yogyakarta. Journal of Medicolegalethics and Hospital Management. 3: 1-15.

Isnandar., Saputra, I, Robiyanto. 2013. Analisis Tingkat Kepuasan Pasien Rawat Inap Di Ruangan Penyakit Dalam Terhadap Pelayanan Di Instalasi Farmasi Rumah Sakit Periode Desember 2011-Februari 2012. Jurnal Manajemen dan Pelayanan Farmasi. 3(4): 231-248.

Keputusan Menteri Kesehatan Nomor 129 Tahun 2008 tentang Standar Pelayanan Minimal Rumah Sakit.

Mulia, D. S. 2019. Evaluasi Kinerja Instalasi Farmasi Rumah Sakit Islam PKU Muhammadiyah Palangka Raya Kalimantan Tengan Dengan Pendekatan Balanced Scorecard. Jurnal Surya Medika. 4(2): 72-78.

Notoatmodjo, S. 2012. Metodologi Penelitian Kesehatan. Rineka Cipta, Jakarta

Nur, Y. D., Haksama, S. 2016. Pengukuran Kinerja Rawat Inap Berdasarkan Perspektif Balanced Scorecard. Jurnal Administrasi Kesehatan Indonesia. 4(1): 67-76.

Peraturan Menteri Kesehatan Republik Indonesia Nomor 72 Tahun 2016 tentang Standar Pelayanan Kefarmasian Di Rumah Sakit.

Priyatno, D. 2010. Paham Analisa Statistik Data dengan SPSS. Madiakom, Yogyakarta.

Rao, C. M., Rao, K. P. 2009. Inventory Turnover Ratio As A Supply Chain Performance Measure. Serbian Journal of Management. 4:41-50.
Saharuddin, T. S., Satibi., Andayani, T. M. 2019. Analisis Perspektif Pembelajaran Dan Pertumbuhan Dalam Mengukur Kinerja Instalasi Farmasi RSUD A.M. Parikesit Tenggarong Kutai Kartanegara Kalimantan Timur Dengan Pendekatan Balanced Scorecard. Jurnal Ilmiah Manuntung. 1(5): 97-105.

Satibi., Fudholi, A., Kusnanto, H., Jogiyanto. 2011. Evaluasi Kinerja Instalasi Farmasi RSUD Kota Yogyakarta dengan Pendekatan Balanced Scorecard. Majalah Farmaseutik. 7(3): 77-86.

Sugiyono. 2013. Metode Penelitian Kuantitatif, Kualitatif dan $R \& D$. Alfa Beta, Bandung.

Sumiati, L. 2019. Analisis Kinerja Instalasi Farmasi Rumah Sakit Umum Daerah Kota Surakarta Dengan Pendekatan Balanced Scorecard [Tesis]. Universitas Setia Budi, Yogyakarta.

Suryani, N. K., FoEh, J. 2018. Kinerja Organisasi. Deepublish,Yogyakarta.

Taher, T. H. 2018. Analisis Pendekatan Balanced Scorecard Mengukur Kinerja Perusahaan. Jurnal Komunikasi Bisnis dan Manajemen. 5(1): 103 - 119.

Zainaro, M . A., Dherlirona., Norabela, A. 2018. Hubungan Kualitas Pelayanan Kesehatan Dengan Kepuasan Pasien Di Klinik Dira Medika Gotong Royong Bandar Lampung Tahun 2017. Holistik Jurnal Kesehatan. 12(2): 126-135. 